\title{
Meal-feeding scheme: twenty years of research in Brazil
}

R.B. Bazotte ${ }^{1}$,

M.R. Batista ${ }^{2}$

and R. Curi ${ }^{3}$
Departamentos de ${ }^{1}$ Farmacia e Farmacologia, and

${ }^{2}$ Ciências M orfofisiológicas, U niversidade Estadual de Maringá,

Maringá, PR, Brasil

${ }^{3}$ Departamento de Fisiologia e Biofísica, Instituto de Ciências Biomédicas,

Universidade de São Paulo, São Paulo, SP, Brasil

\section{Correspondence \\ R. Curi \\ Departamento de Fisiologia e \\ Biofísica, ICB, USP \\ Av. Prof. Lineu Prestes, 1524 \\ 05508-900 São Paulo, SP \\ Brasil}

Research supported by FAPESP, CNPq, CAPES, the British Council, and PRONEX.

This review was written to celebrate the retirement of Dr. Naomi S. Hell.

Received November 12, 1999 Accepted June 14, 2000

\section{Abstract}

Naomi Shinomiya Hell was the first researcher to investigate the physiological adaptations to a meal-feeding scheme (MFS) in Brazil. Over a period of 20 years, from 1979 to 1999, Naomi's group determined the physiological and metabolic adaptations induced by this feeding scheme in rats. The group showed the persistence of such adaptations even when MFS is associated with moderate exercise training and the performance to a session of intense physical effort. The metabolic changes induced by the feeding training were discriminated from those caused by the effective fasting period. Naomi made an important contribution to the understanding of the MFS but a lot still has to be done. One crucial question still remains to be satisfactorily answered: what is the ideal control for the MFS?

\section{Characterization of the meal-feeding scheme}

Bernardo A. Houssay first employed the meal-feeding scheme (MFS) 52 years ago (1). Since then, a number of studies on animals and humans $(2,3)$ have shown metabolic alterations induced by MFS. In Brazil, Naomi S. Hell was the first researcher to investigate the physiological adaptations to MFS (4). The MFS on which Naomi S. Hell worked since 1979 (4-9) consists of free access to food for a single daily 2 -h period, offered at a fixed mealtime, usually between 8:00 and 10:00 a.m., with no restriction of the amount of food. In rats, this feeding scheme replaces the usual free access to food, which involves a high frequency of food intake distributed throughout the daytime. Thus, the animal is trained to eat at a

\section{Key words}

- Meal-feeding scheme

- Metabolism

- Exercise

- Fasting

- Liver fixed mealtime. However, during a 2-h period, the rat cannot ingest the same amount of food consumed in $24 \mathrm{~h}$, and so is also submitted to a condition of food restriction.

MFS has received several denominations such as food restriction (4), meal-feeding (10), stuff and starve feeding program (11), meal eating (12), restricted daily feeding schedule (13), controlled feeding schedule (14), and predictable feeding schedule (15).

Different groups have employed several variants of MFS. These feeding schedules are not fully comparable with our experimental model. This is the case for the diurnal cycles (16) and for studies that use $2 \mathrm{~h}$ of feeding divided into two 1-h periods per day, from 8:00 to 9:00 $\mathrm{h}$ and from 16:00 to 17:00 $\mathrm{h}(17)$, and studies with simultaneous restriction of food and water (18). Also, in some experiments the animals are submitted to $2-\mathrm{h}$ 
feeding/22-h fasting, with $50 \%$ (19), $60 \%$ (20) or $70 \%$ (21) of the amount of food ingested ad libitum by the animals offered during the eating period. Additionally, there are reports of 2/46 (22), 8/40 (23) and 4/20 h (24) feeding/fasting schemes.

Most of these studies have been carried out using daily 2 -h feeding. However, there are studies employing 1/23 (25), 3/21 (26), 4/20 (27), 6/18 (28) and 8/16 h (29) feeding/ fasting schemes. The results obtained from these experiments are in many aspects comparable to the $2 / 22$-h feeding/fasting scheme. However, a period of free access to food for more than $8 \mathrm{~h}$ should be analyzed with caution since this feeding schedule is closer to the condition of free-fed animals. On the other hand, a feeding period shorter than $1 \mathrm{~h}$ may be considered extremely stressful for the animals (30).

Another aspect of variation in the MFS is the fixed mealtime. In our studies the meal usually starts at 8:00 h. However, there are studies in which the meal starts at 7:00 (31), 9:00 (28), 12:00 (13), 14:00 (27), 16:00 (32), 17:00 (33) and 20:00 h (34). Additionally, several investigators have demonstrated that the physiological adaptations were qualitatively similar when meals were offered either during the day or during the night (3537). These results allow us to postulate that the mealtime itself plays a minor role in the establishment of the adaptations to MFS. However, a fixed mealtime is of crucial importance for the establishment of the physiological changes in response to MFS (7). In fact, studies with a fixed mealtime, but without specification of the daily period of access to food have reported similar observations $(1,38)$.

The importance of the disciplined mealtime as a factor that assures animal survival was demonstrated by the fact that the typical adaptations to MFS disappear when food is offered at unpredictable times $(7,15,30,39)$.

Another aspect to be considered is the duration of the MFS. Lima et al. (35) sug- gested that one week of training is enough to promote alterations in carbohydrate metabolism. However, this period was not sufficient to affect lipogenesis (40). Therefore, the metabolic adaptations are progressively established and vary with the conditions employed.

In addition to the rat (4-11), other species have also been utilized to study MFS. There are studies employing pigs (12), chickens (40), mice (37), and even monkeys (26). The results obtained for the different species are not fully comparable.

\section{Physiological changes induced by MFS}

Rats submitted to MFS present hyperphagia, gastric hypertrophy, increased gastric capacitance, and slower gastric emptying (5-7). The changes in the digestive tract also include intestinal mucosa hypertrophy and increased glucose absorption (22) and disaccharidase activity (16). These alterations suggest the occurrence of increased efficiency of food utilization in MFS animals $(11,22)$. Rats submitted to MFS also present higher disaccharidase (41), hexokinase (42), glucose-6-phosphate dehydrogenase, and 6phosphogluconate dehydrogenase activities $(42,43)$ in the intestine. It is important to point out that several authors believe that the major adaptations to MFS occur in the gastrointestinal tract, consequently leading to other physiological changes.

MFS rats show a $50 \%$ reduction in daily spontaneous activity (22). In contrast, an increased anticipatory activity can be observed immediately before the fixed mealtime $(13,44,45)$. The intensification of spontaneous activity before mealtime is an expected behavior since the animals ingest half of the daily normal consumption during only $2 \mathrm{~h}$ of restricted mealtime.

Blood insulin and glucagon levels peak immediately before mealtime, but are reduced during the inter-meal period $(33,46)$. 
Likewise, MFS animals receiving an intraperitoneal load of glucose present an increased sensitivity to insulin (4). In agreement with these observations, O'Dea et al. (17) found higher sensitivity to insulin in the aorta. Moreover, MFS rats show lower blood levels of T3, T4 and TSH (47).

The adaptation to MFS seems to be fully dependent on the adrenal gland. In fact, adrenalectomized rats do not survive MFS (36). Challet et al. (21) described a deviation in the peak of plasma ACTH and corticosterone levels towards the fixed mealtime. Wilkinson et al. (48) observed maximal responsiveness of the adrenal cortex to ACTH at that time. Saito and Kato (49) proposed that the changes in corticosterone peak reflect part of the anticipatory response to the predictable mealtime. During the meal, however, an elevation of circulating vasopressin has been reported (2).

MFS leads to an increase in the rate of lipogenesis in both the liver and adipose tissues of rats $(22,27,43)$. Similar findings have been reported for pigs (12) and chickens (40). The increased rate of lipogenesis is at least partially due to increased pyruvate dehydrogenase (50) and lipoprotein lipase (51) activity.

MFS induces several metabolic adaptations which are particularly pronounced during the training fasting period, i.e., $22 \mathrm{~h}$ of fasting for an MFS of $2 / 22 \mathrm{~h}$. Better glycemia maintenance during the inter-meal period (6), increased tolerance to intraperitoneal and intravenous glucose administration, and higher capacity to recover from hypoglycemia induced by insulin administration (4) have been described. On the other hand, the response of insulin secretion to a glucose stimulus is markedly decreased by MFS (46). Concerning fatty acids, MFS reduces the mobilization of this metabolite during the inter-meal period $(5,52)$.

The changes in glucose and fatty acid metabolism induced by MFS persist even when this feeding condition is maintained for a prolonged period of time, such as 20 weeks (52). Furthermore, these metabolic adaptations are not affected by exercise training (53) but are fully abolished when rats are freely fed $(8,54)$. In turn, when rats trained for MFS for 4 weeks are submitted to a single exercise session there is a slow rate of muscle glycogen breakdown (55), which may promote a better performance and/or resistance to exhaustion (56).

Due to the fact that MFS rats show increased anticipatory activity and higher food intake during mealtime, several researchers have investigated the participation of the central nervous system (CNS) in this feeding scheme. It has been demonstrated that MFS rats with lesion of the ventromedial hypothalamus lose the anticipatory behavior and the corticosterone peak observed during the fixed mealtime $(13,18)$. Since anticipatory activity is recovered two weeks after ventromedial hypothalamic lesion (49), other areas of the CNS must be also involved in the adaptation to MFS. In fact, Yoshihara et al. (57) observed increased neuropeptide Y levels in the solitary tract nucleus and paraventricular nucleus of the hypothalamus at mealtime. This information illustrates the complexity of the systems that modulate feeding behavior in MFS animals.

The longevity of mice trained for MFS has also been investigated (37). Control animals took 220 weeks to die, whereas MFS mice lived significantly longer. These results confirm the findings previously obtained in rats submitted to chronic food deprivation (19). A recent study has shown that food restriction causes important metabolic changes that play a role in terms of a much longer animal survival (58). The authors have shown that most alterations caused by aging are either completely or partially prevented by caloric restriction, the only intervention known to retard aging in mammals. Transcriptional patterns of calorie-restricted animals suggest that caloric restriction retards the aging process by causing a metabolic 
shift toward increased protein turnover and decreased macromolecular damage.

\section{The liver and the metabolic adaptations to MFS}

The liver plays a central role in the metabolic adaptations to MFS. After a meal, increased amino acid transport and increased tyrosine transaminase, pyruvate dehydrogenase, tyrosine aminotransferase and ornithine decarboxylase activities occur in the liver of MFS rats $(14,29,59)$ Additionally, lipid accumulation occurs due to an increased lipogenic capacity of adipose tissue $(40,43)$.

Livers from MFS animals show glycogen accumulation $(5,6)$ and resistance to its catabolism during the inter-meal period $(6,7)$. Changani et al. (60) demonstrated increased $\left[{ }^{13} \mathrm{C}\right]$-glucose incorporation into $\left[{ }^{13} \mathrm{C}\right]$-glycogen in MFS rats. In fact, several studies have found glycogen accumulation in white and red muscle (5), adipose tissue (22), and diaphragm (40) of MFS animals. It is interesting to note that glycogen content not only of the liver, but also of white and red muscle continues to be increased when this feeding scheme is associated with daily physical exercise $(53,55)$. On the other hand, we have recently found that the higher hepatic glycogen concentration of MFS rats cannot be fully attributed to the feeding training but also is a consequence of the fasting period (9).

The increased hepatic capacity to store glycogen during the inter-meal period can be observed as early as after the first week (5), becoming more intense when this feeding scheme is prolonged for four (7) or twenty (52) weeks. Such physiological changes also occur when MFS is associated with a high carbohydrate (25) diet. Furthermore, increased resistance to hepatic glycogen breakdown has been found during insulin-induced hypoglycemia (4). However, the disciplined mealtime is an important component for the establishment of elevated liver glycogen content. In fact, if meals are offered randomly at unpredictable times this metabolic change does not take place (7).

Using the liver perfusion technique, we have found decreased glucose and ketone body production and lower responsiveness to epinephrine in the liver from MFS rats (6). In spite of the relevance of hepatic gluconeogenesis for glucose production during starvation, there are only few studies on this metabolic pathway in the liver of MFS rats. The results obtained in these studies will be described in the next section of this review.

\section{Are the physiological adaptations of MFS determined by the higher food intake per se or are they a consequence of the disciplined feeding scheme?}

The feeding scheme of a single daily meal offered at a fixed mealtime (2-h feeding/22-h food deprivation) causes a progressive increase in daily food ingestion, leading to hyperphagia after a few days of feeding training (4-7). It should be pointed out that the control animals in these studies were free fed and killed after a 22-h fast and refeeding for $2 \mathrm{~h}$. Thus, the condition of control rats is similar to that of MFS rats submitted to the first day of feeding training. Although this group is an appropriate control for specific purposes, the amount of food ingested by the rats is about $50 \%$ lower than that ingested by MFS animals during the mealtime (6,7). Thus, the groups were probably not submitted to the same effective fasting period, and a question can then be raised: are the physiological adaptations of MFS rats determined by the higher food intake per se or are they caused by the disciplined feeding scheme?

To answer this question, in a recent study (9) we compared rats refed on the 1st (untrained) and 13th days of the training period. Both groups received $5 \mathrm{~g}$ of food $(70 \%$ of the amount of food ingested by MFS rats on the 1st day of training) in order to differentiate physiological changes caused by higher food 
intake $(6,35)$ from those due to the feeding scheme itself. In addition, a third group consisting of MFS rats refed on day 13 with approximately $75 \%$ (12 g) of the food ingested by MFS rats on the 13th day of the feeding training was included. The results showed that part of the adaptation to MFS is a consequence of the feeding training (higher food intake, increased gluconeogenesis from pyruvate), whereas other changes (gastric and intestinal emptying, hepatic glycogen content and increased gluconeogenesis from glycerol) correlate well with the effective period of fasting. In addition, both feeding training and effective period of fasting influence hepatic gluconeogenesis from L-lactate and L-glutamine (9).

The importance of discriminating between the role played by the amount of food ingested in the last meal and the effect of the feeding scheme can be easily observed by an analysis of the data published by Leveille and Chakrabarty as early as in $1968(3,10)$. These authors published two papers in the same year with opposite results. In the first publication they described increased hepatic PEPCK activity in MFS rats. However, in that study they compared the MFS group submitted to a 22-h fast with a group of freeeating rats. In contrast, in the second study, the conversion of $\left[{ }^{14} \mathrm{C}\right]$-pyruvate to $\left[{ }^{14} \mathrm{C}\right]-$ glucose was reduced in the liver of MFS rats. In the latter study, however, the authors used 22 -h food-deprived rats as controls. Therefore, they used two different controls and, not surprisingly, reached opposite conclusions, i.e., increased and decreased hepatic gluconeogenesis capacity due to MFS. In our recent investigation (9), employing different controls, we came to the conclusion that hepatic gluconeogenesis is in fact influenced by feeding training, effective fasting period or both. These factors are able to affect liver metabolism in such a way that gluconeogenesis rates are differently affected depending on the glucose precursor, i.e., glycerol, pyruvate, alanine or glutamine.

Since the feeding training and the period of fasting influence the physiological changes observed in MFS rats, a new question can be raised: what is the ideal control for MFS? The answer to this question can motivate substantial investigation on MFS in the coming years. However, a lot still has to be done concerning the adaptations to MFS and its possible benefits and risks for health.

Naomi Shinomiya Hell was born in Cafelândia, SP, Brazil, in 1943. Married to Kurt Günther Hell, she graduated in Biological Sciences from the University of São Paulo in 1969. At the same University, working with Dr. Armando de Aguiar Puppo, she obtained her PhD in 1973. For further training in her specialty in physiology, Naomi left Brazil (1974) to work as an NIH fellow at the University of Wisconsin, WI, USA. Back to Brazil in 1975, Naomi started working at the University of São Paulo as an Assistant Professor. From 1975 to her retirement in 1998 , Naomi studied the physiological adaptations to feeding schedules and became one of the leading scientists in this field. Her scientific leadership was fundamental in the training of a generation of scientists, who today are continuing her work. Another relevant contribution by Naomi was the installation of the Laboratory of Endocrinology in the Department of Physiology and Biophysics, University of São Paulo. Her scientific and academic contribution to Brazilian science was recognized during the 1999 FESBE meeting when the first (Ana L. Sawaya, Fábio B. Lima, Roberto B. Bazotte, Rui Curi, Ubiratan F. Machado) and the second generation of scientists trained by Naomi paid a joint tribute to the woman who devoted her life to obtaining better research conditions for her followers. 


\section{References}

1. Houssay BA \& Martínez D (1947). Experimental diabetes and diet. Science, 105: 548-549.

2. Leal AMO \& M oreira AC (1997). Food and the circadian activity of the hypothalamicpituitary-adrenal axis. Brazilian J ournal of Medical and Biological Research, 30: 1391-1405.

3. Chakrabarty K \& Leveille GA (1968). Influence of periodicity of eating on the activity of various enzymes in adipose tissue, liver and muscle of the rat. J ournal of Nutrition, 96: 76-82.

4. Hell NS, Oliveira LBC, Dolnikoff MS, Scivoletto R \& Timo-laria C (1980). Changes of carbohydrate metabolism caused by food restriction, as detected by insulin administration. Physiology and Behavior, 24: 473-477.

5. Curi R, Hell NS, Bazotte RB \& Timo-laria C (1984). Metabolic performance of free fed rats subjected to prolonged fast as compared to the metabolic pattern in rats under long term food restriction. Physiology and Behavior, 33: 525-531.

6. Bazotte RB, Curi R \& Hell NS (1986). Food restriction: influence of age on body weight gain and responsiveness of water intake to food ingestion. Arquivos de Biologia e Tecnologia, 29: 465-471.

7. Bazotte RB, Curi R \& Hell NS (1989). Metabolic changes caused by irregularfeeding schedule as compared with meal feeding. Physiology and Behavior, 46: 913.

8. Curi R, Hell NS \& Timo-laria C (1987). Reversibility of the metabolic adaptations to meal-feeding in rats. Biochemical Society Transactions, 15: 278-279.

9. Batista $M R$, Ferraz $M$ \& Bazotte RB (1997). Are physiological changes in mealfed rats determined by the amount of food ingested in the last meal or due to feeding schedule? Physiology and Behavior, 62: 249-253.

10. Leveille GA \& Chakrabarty K (1968). In vivo and in vitro studies of gluconeogenesis in meal-fed and nibbling rats. J ournal of Nutrition, 96: 397-402.

11. Hollifield G \& Parson W (1962). Metabolic adaptations to a "stuff and starve" feeding program. II. Obesity and the persistence of adaptive changes in adipose tissue and liver occurring in rats limited to a short daily feeding period. J ournal of Clinical Investigation, 41: 250-253.

12. Allee GL, Romsos DR, Leveille GA \& Baker DH (1972). Metabolic adaptation induced by meal-eating in the pig. J ournal of Nutrition, 102: 1115-1122.

13. Inouye TS (1982). Ventromedial hypothalamic lesions eliminate anticipatory activities of restricted daily feeding schedules in the rat. Brain Research, 250: 183-187.

14. Baril EF \& Potter VR (1968). Systematic oscillations of amino acid transport in liver from rats adapted to controlled feeding schedules. J ournal of Nutrition, 95: 228237.

15. Ulm RR, Volpicelli R, Cerpa R \& M cIntyre $K$ (1987). Weight gain in postweaned rats as a function of predictable and unpredictable feeding schedules. Physiology and Behavior, 40: 287-289.

16. Saito M, Kato H \& Suda M (1980). Circadian rhythm of intestinal disaccharidases of rats fed with adiurnal periodicity. American J ournal of Physiology, 238: G97G101.

17. O’Dea K, Kaplovitz H \& Marino A (1977). Effect of meal-feeding on insulin sensitivity and incorporation of [U-14C]glucose into lipids in rat aorta. J ournal of Nutrition, 107: 1896-1901.

18. Krieger DT, Crowley WR, O'Donuhue TL $\&$ J acobowitz DM (1980). Effects of food restriction on the periodicity of corticosteroids in plasma and on monoamine concentrations in discrete brain nuclei. Brain Research, 188: 167-174.

19. Masoro EJ , Yu BP \& Bertrand HA (1982). Action of food restriction in delaying the aging process. Proceedings of the $\mathrm{Na}$ tional Academy of Sciences, USA, 79: 4239-4241.

20. Brownlow BS, Park CR, Schwartz RS \& Woods SC (1993). Effect of meal pattern during food restriction on body weight and recovery after refeeding. Physiology and Behavior, 53: 421-424.

21. Challet E, Pevet $P$, Vivien-Roels $B \&$ Malan A (1997). Phase-advanced daily rhythms of melatonin, body temperature, and locomotor activity in food-restricted rats fed during daytime. J ournal of Biological Rhythms, 12: 65-79.

22. Leveille GA (1972). Lipogenic adaptations related to pattern of food intake. Nutrition Reviews, 30: 151-155.

23. Whittle ED \& Potter VR (1968). Systematic oscillations in the metabolism of orotic acid in the rat adapted to a controlled feeding-schedule. J ournal of Nutrition, 95: 238-246.

24. Yi I, Stephan FK \& Bays ME (1995). Activity-stress ulcers in rats: the role of preentrainment to meal time. Physiology and Behavior, 58: 67-73.
25. Tepperman J \& Tepperman HM (1958). Effects of antecedent food intake pattern on hepatic lipogenesis. American J ournal of Physiology, 193: 55-64.

26. Sulzman FM, Puller CA \& Moore-Ede MC (1977). Feeding time synchronizes primate circadian rhythms. Physiology and Behavior, 18: 775-779.

27. Lanza-J acoby S, Stevenson NR \& Kaplan ML (1986). Circadian changes in serum and liver metabolites and liver lipogenic enzymes in ad libitum and meal-fed, lean and obese Zucker rats. J ournal of Nutrition, 116: 1798-1809.

28. Kato H, Saito M \& Suda M (1980). Effect of starvation on the circadian adrenocortical rhythm in rats. Endocrinology, 106: 918-921.

29. Watanabe M, Potter VR \& Pitot HC (1968) Systematic oscillations in tyrosine transaminase and other metabolic functions in liver of normal and adrenalectomized rats on controlled feeding schedules. J ournal of Nutrition, 95: 207-227.

30. Welker RL, Garber J \& Brooks F (1977). Stress as a function of irregular feeding of food deprived rats. Physiology and Behavior, 18: 639-645.

31. Braun T, Vrana A \& Fabry P (1967). Enhanced hypoglycaemic effect of exogenous insulin associated with an increased response of adipose tissue and diminished response of the diaphragm in meal fed rats. Experientia, 23: 468-470.

32. Cardell RR (1971). Action of metabolic hormones on the fine structure of rat liver cells. I. Effects of fasting on the ultrastructure of hepatocytes. American J ournal of Anatomy, 131: 21-32.

33. Ip MM, Ip C, Tepperman HM \& Tepperman J (1977). Effect of adaptation to meal-feeding on insulin, glucagon and cyclic nucleotide-protein kinase system in rats. J ournal of Nutrition, 107: 746-757.

34. Saito $M \& \&$ Kato $H$ (1981). Circadian changes in the plasma insulin response to food intake in rats and their relation to the feeding schedule. Biomedical Research, 2: $285-290$.

35. Lima FB, Hell NS, Timo-laria C, Dolnikoff MS \& Pupo AA (1982). Carbohydrate metabolism and food intake in food restricted rats: effects of an unexpected meal. Physiology and Behavior, 29: 931-937.

36. Berdanier $C D$, Wurdeman $R \&$ Tobin RB (1976). Further studies on the role of the adrenal hormones in the responses of rats to meal-feeding. J ournal of Nutrition, 106: 1791-1800. 
37. Nelson W \& Halberg $F$ (1986). Meal-timing, circadian rhythms and life span of mice. J ournal of Nutrition, 116: 22442253.

38. Smith M, Pool R \& Weinberg H (1962). The role of bulk in the control of eating. J ournal of Comparative and Physiological Psychology, 55: 115-120.

39. Valle FP (1981). Detrimental effects of irregular meals on rat's ability to adjust to meal feeding. American J oumal of Psychology, 94: 3-11.

40. Leveille GA (1966). Glycogen metabolism in meal-fed rats and chicks and the time sequence of lipogenic and enzymatic adaptive changes. J ournal of Nutrition, 90: 449-460.

41. Suda M \& Saito M (1979). Coordinative regulation of feeding behavior and metabolism by a circadian timing system. In: Suda M, Hayaishi O \& Nakagawa H (Editors), Biological Rhythms and their Central Mechanisms. Elsevier/North-Holland Biomedical Press, New York.

42. Romsos DR \& Leveille GA (1974). Influence of periodicity of eating on intestinal glycolytic enzymes in the rat. Comparative Biochemistry and Physiology, 49: 533-540.

43. Leveille GA (1970). Adipose tissue metabolism: influence of periodicity of eating and diet composition. Federation Proceedings, 29: 1294-1301.

44. Walcott EC \& Tate BA (1996). Entrainment of aged, dysrhythmic rats to a restricted feeding schedule. Physiology and Behavior, 60: 1205-1208.

45. Morse AD, Russell J C, Hunt TW, Wood
GO, Epling WF \& Pierce WD (1995). Diurnal variation of intensive running in fooddeprived rats. Canadian J ournal of Physiology and Pharmacology, 73: 1519-1523.

46. Santos J r A, Carpinelli AR \& Curi R (1989). The effect of controlled feeding conditions on the metabolic characteristics of rats. Physiology and Behavior, 45: 529532.

47. Cokelaere M, Decuypere E, Flo G, Darras VM \& Kuhn ER (1996). Influence of feeding pattem on thyroid hormones in longterm food-restricted rats. Hormonal and Metabolic Research, 28: 315-318.

48. Wilkinson CW, Shinsako J \& Dallman MF (1979). Daily rhythms in adrenal responsiveness to adrenocorticotropin are determined primarily by the time of feeding in the rat. Endocrinology, 104: 350-359.

49. Saito $M \& \&$ Kato $H$ (1985). Circadian anticipatory response to food intake in behavioral and endocrine functions. In: Hiroshige $T \&$ Honma K (Editors), Circadian Clocks and Zeitgebers. University Press, Hokkaido, 146-156.

50. Holness MJ \& Sugden MC (1989). Comparison of tissue pyruvate dehydrogenase activities on re-feeding rats fed ad libitum or meal-fed rats with a chow-diet meal. Biochemical J oumal, 262: 321-325.

51. Sugden MC, Grimshaw RM \& Holness MJ (1994). Regional variations in metabolic responses of white adipose tissue to food restriction. American J ournal of Physiology, 267: E892-E899.

52. Curi R \& Hell NS (1986). Metabolic changes of twenty weeks food-restriction schedule in rats. Physiology and Behav- ior, 36: 239-243.

53. Curi R, Hell NS \& Timo-laria C (1990). Meal-feeding and physical effort. 1 . Metabolic changes induced by exercise training. Physiology and Behavior, 47: 869873.

54. Curi R, Bazotte RB, Hell NS \& Timo-laria C (1989). Reversibility of metabolic changes induced by feeding schedule in rats. Physiology and Behavior, 45: 249-254

55. Curi R, Hell NS \& Timo-laria C (1990). Meal-feeding and physical effort. 2. Metabolic changes induced by an acute exercise. Physiology and Behavior, 47: 875879.

56. Curi R (1992). Metabolic and hormonal adaptations to diet restriction. Nutrition, 8: 56-57.

57. Yoshihara T, Honma S \& Honma K (1996). Effects of restricted daily feeding on neuropeptide $Y$ release in the rat paraventricular nucleus. American J ournal of Physiology, 270: E589-E595.

58. Lee CK, Klopp RG, Weindruch R \& Prolla TA (1999). Gene expression profile of aging and its retardation by caloric restriction. Science, 285: 1390-1393.

59. Sugden MC, Grimshaw RM \& Holness MJ (1993). The regulation of hepatic carbon flux by pyruvate dehydrogenase and pyruvate dehydrogenase kinase during long-term food restriction. Biochemical J ournal, 296: 217-223.

60. Changani KK, Williams SC \& Iles RA (1994). In vivo hepatic glucose and glycogen metabolism in meal fed rats. Biochemical Society Transactions, 22: 126S. 